Article

\title{
A Novel Improvement Strategy of Competency for Education for Sustainable Development (ESD) of University Teachers Based on Data Mining
}

\author{
Sung-Shun Weng ${ }^{1}\left(\mathbb{D}\right.$, Yang Liu ${ }^{1, * \mathbb{D}}$, Juan Dai $^{2}$ and Yen-Ching Chuang ${ }^{3}$ \\ 1 Department of Information and Finance Management, National Taipei University of Technology, No. 1, \\ Sec. 3, Zhongxiao E. Rd., Taipei 10608, Taiwan; wengss@ntut.edu.tw \\ 2 School of Continuing Education, Beijing Institute of Technology, No. 5, South Zhongguancun Street, \\ Haidian Dist., Beijing 100081, China; haomoon@163.com \\ 3 Graduate Institute of Urban Planning, College of Public Affairs, National Taipei University, No. 151, \\ University Rd., Sanxia Dist., New Taipei City 23741, Taiwan; yenching.chuang@gmail.com \\ * Correspondence: t106749404@ntut.org.tw
}

Received: 2 March 2020; Accepted: 27 March 2020; Published: 29 March 2020

\begin{abstract}
Competency for ESD (education for sustainable development) of university teachers is the key to the sustainable development of higher education. Developing teachers' competency for ESD poses a new challenge for Chinese universities. Ideally, a new faculty development system should be established. However, this strategy is not feasible because of cost concerns, and improving competency for ESD by using the existing teacher competency training system is preferred. Therefore, this paper employed a specific data mining method to create a relationship model between the existing teacher competency system and the ESD competency according to teacher evaluation data. The developed model was used to analyze the teachers' core competencies that are critical to ESD competency and derive decision rules for formulating improvement strategies. The teacher competency model was applied to the International Scholarly Exchange Curriculum (ISEC) program implemented at regional universities in China to conduct an empirical case study. The results of this study are anticipated to enable the formulation of an effective and appropriate strategy for improving teachers' competency for ESD in the existing teacher development system.
\end{abstract}

Keywords: education for sustainable development (ESD); competency for ESD; teacher training; higher education; strategies for improving teachers' competency; dominance-based rough set approach (DRSA); data mining

\section{Introduction}

To achieve the Sustainable Development Goals 2030, the United Nations Educational, Scientific, and Cultural Organization established an organization named International Task Force on Teachers for Education 2030 in September 2019. The organization consists of 130 members, 85 of whom work in national governments. According to the aforementioned organization, teachers are one of the most influential factors affecting education equity, opportunities, and quality, as well as the continuity of global development [1]. To fulfil its commitment to the Sustainable Development Goals 2030, the Chinese government [2] issued China's Education Modernization 2035, which aims to introduce Chinese wisdom, experience, and programs to global education development through practical actions. The policy incorporates eight fundamentals of China's education modernization plan, namely ethics prioritization, well-balanced development, lifelong learning, personalized teaching, integration of knowledge and practice, people orientation, integrated development, and coconstruction and sharing. To realize these principles, the Chinese government implemented one of its ten major education 
modernization strategies: formulating a team of high-quality, professional, and innovative teachers and continually building teacher teams as a part of basic missions [2]. Thus, university teachers with high knowledge and competency levels are crucial to China's continual education development [3,4].

Education for sustainable development (ESD), which has attracted increasing attention, has caused new challenges in education development, especially to teachers' competencies. Nevertheless, a limited number of studies have been conducted on teachers' competency for ESD [4]. Moreover, observing and evaluating these competencies are considerable challenges [5]. Few studies have explored models on teacher competency for ESD. According to the 10-year sustainable development and ESD programs of the United Nations, Rauch and Steiner [6] explored, in detail, the factors affecting Austrian teachers' competency for ESD and established an ESD competency model. Bertschy, Künzli, and Lehmann [4] examined and compared the advantages and disadvantages of two models on educators' competencies, namely the curriculum, sustainable development, competencies, teacher training (CSCT) competence model and competences in education for sustainable development (ECE) model. The aforementioned two models emphasize the ESD competency that teachers need in a particular area [7]. Parker [8] investigated methods for developing teachers' interdisciplinary competency in higher education, which is one of the key elements for ESD competency. In summary, studies have focused on the key elements of competency for ESD but not on the correlation between ESD competency and other types of teacher competencies.

Dr Montoya [9], the director of the United Nations Educational, Scientific, and Cultural Organization Institute for Statistics, indicated that ESD is based on teachers' continual learning and training and rooted within their continual improvement in the training. To attain the sustainable development of China's higher education, China's universities must strengthen and adjust the directions and policies of university teacher ESD competency training. However, most Chinese universities have long adopted a pre-established teacher competency model and training system. Abolishing the system and establishing a new ESD competency model and training system would cost a large amount of social and economic resources. Therefore, using the existing teacher development mechanism to improve teachers' competency for ESD is a compromise and an appropriate strategy. This strategy is particularly useful for regional universities, which have limited resources. In the present study, according to the evaluation data on university teachers' competencies, the rough-dominance set approach (DRSA), a data mining method, was employed to establish a new ESD competency model for Chinese university teachers. This novel model focuses on the relationship between teachers' competency for ESD and their other types of competencies. Thus, the model assists decision makers in systematically planning teacher training and in improving and developing the competency for ESD through only a limited amount of adjustment in the existing training and development activities. Several original crucial competency indicators can be developed continuously, and competency for ESD can be reinforced without incurring high costs or abandoning the existing teacher development system.

This paper employed the DRSA to establish a model on the behavior pattern between the existing teacher competencies (i.e., condition attributes) and competency for ESD (i.e., decision attributes). A set of rules, shown in the form of "if ... then", is derived for construing the connection between conditional attributes and decision attributes. DRSA has the following advantages: (1) the decision rules of competency for ESD are described using natural languages, which enables decision makers and managers to easily understand the actual behaviors involved in the competencies; (2) the core competency attributes in the existing teacher competency model that are closely related to competency for ESD are identified to enable decision makers and managers to reduce resource investment for the attributes not highly related to competency for ESD without affecting the development of the competencies; and (3) the decision rules facilitate the enhancing of competency for ESD through the improvement of other types of competencies in the existing teacher competency model. The DRSA-based model derives a rule according to teacher competency evaluation data to enable decision makers to improve teachers' competency for ESD. Accordingly, universities can formulate appropriate strategies for adjusting the existing teacher development system in a limited capacity to improve teachers' 
competency for ESD. This study focused on the International Scholarly Exchange Curriculum (ISEC) programme, the primary targets of which were regional universities in China. Most Chinese universities are regional. They comprise the highest proportion of university teachers in China's higher education system. Thus, the data obtained from the ISEC program have high representativeness.

Section 2 introduces a review of ESD-related studies. The research procedure of the DRSA is presented in Section 3. Subsequently, an empirical study on education pilot projects implemented in Chinese universities is analyzed. Next, there are some discussions for an interpretation of the research consequences. Finally, the conclusions of this study are provided, including the research ideas, contributions, limitations, and future research directions.

\section{ESD and Competency for ESD}

The concept of ESD [10] first appeared in Agenda 21, which was released by the United Nations Conference on Environment and Development in 1992. According to the agenda, education is crucial for facilitating sustainable development and advancing people's capability to solve problems pertinent to the environment and development. ESD focuses on preparing young generations in becoming responsible citizens. It aims to enable them to improve society through sustainable means and to become responsible for themselves and their offspring through the concept of sustainable development $[11,12]$. Due to problems related to the environment and societies, ESD requires qualitative changes in education ideas, methods, and goals [13]. In the background of higher education for sustainable development (HESD), the conceptualization of teachers' competency for ESD and their expression in curricula teaching are highly complex. Increasing attention has been given to the methods that universities from around the world, and their stakeholders, can use to foster teachers' ESD competency [14].

Competencies are active combinations of knowledge, abilities, and intentions that enable people to successfully and responsibly respond to changing conditions [15]. The concept of competency was considered an important milestone in the direction of teaching for sustainable development. Correspondingly, teachers' ESD competency was then proposed [15]. The successful implementation of ESD requires participation by competent and dedicated teachers, who are crucial to the promotion of reforms. Teacher education must involve the active consideration of the knowledge and competencies required by teachers for the positive promotion of ESD-oriented reforms [16]. However, according to Bertschy, Künzli, and Lehmann [4], the research on teachers' competency for ESD is a relatively new topic, and previous research is limited. Research on ESD, which emerged in 2009, is yet to mature. Studies have explored ESD from two directions: (1) analyzing which elements should be considered as part of teachers' competency for ESD and (2) developing an ESD competency model.

Studies have indicated that society-oriented teaching competencies or competencies based on social science must be developed [17-19]. Burmeister, Rauch, and Eilks [12] stressed teaching competencies that are problem-oriented and based on social critiques. Weinert [15] contended that ESD must involve teachers in improving their sustainable competencies. Parker [8], as well as Bürgener and Barth [16], contended that teachers' interdisciplinary teaching competencies are critical in the training of students' sustainable development competencies. According to Adomssent, Godemann, Michelsen, et al. [20], in higher education, teachers' competencies in providing students with a combination of formal and informal learning environments are crucial. In an experiment at James Cook University, Tomas, Girgenti, and Jackson [21] reported that practice-oriented teaching competencies should be reinforced to strengthen ESD. In a study on higher education institutions in Europe, Lozano, Barreiro-Gen, Lozano, et al. [22] verified that teachers' understanding of new teaching methods and capability of suitably using them could reinforce students' sustainable development competencies effectively.

In addition to the elements of ESD competency for teachers, studies have examined the frameworks and models of these competencies. Selvi [23] described teachers' competencies by using a framework with nine dimensions: domain competency, research competency, curriculum competency, lifelong learning competency, social and cultural competency, emotional competency, communication competency, information and communication technology competency, and environmental competency. 
Sleurs [24] established the CSCT model, which incorporates four elements of competency for ESD (i.e., curriculum, sustainable development, competencies, and teacher training) and emphasizes individual teachers. In addition to teachers' professional competence, CSCT incorporates their overall personalities as well as individual and social behaviors into the factors of sustainable development. CSCT emphasizes comprehensive educational incentives and stresses the use of holistic approaches to solving the complexity of ESD competency. Achieving ESD goals requires teachers to possess specific competencies that can be applied for general educational product innovation [25]. The ECE model presented by the United Nations Economic Commission for Europe [26] suggested defining the educator in four competence fields and three target domains. Rauch and Steiner [6] developed the competences for ESD in teacher education (KOM-BiNE) model for the in-depth analysis of teachers' competencies related to interdisciplinary topics, such as sustainable development and ESD. The model was a part of a major project of the European Union, which was based on competencies in fields of action. In a three-year project funded by the European Union, Vare, Arro, de Hamer, et al. [27] developed a practical ESD educator authentication model.

The aforementioned studies contributed critically to the conceptualization of competency for ESD. The elements and descriptions of competency of ESD have become more and more transparent; the ESD competency model is still being developed, providing a practical reference for strengthening teachers' ESD competency.

\section{Methodology}

Pawlak [28] developed a soft computing method named rough set theory (RSA), which involves determining the behavior pattern between decision and condition attributes on the mathematical basis of set theory. The RSA also enables the simultaneous processing of quantitative and qualitative data [29]. The theory enables the processing of inconsistent information without prior knowledge [30], such as probability distribution. Moreover, it can express the behavior pattern behind data through the 'if-then' decision rule, which enables decision makers to comprehend the correlation between attributes [31,32] and determine additional information relevant to decision-making, such as sets of core condition attributes, sets of reduced condition attributes, levels of importance of condition attributes, and the decision rules for classifications of decision attributes. Compared with other commonly employed black-box algorithms, such as the artificial neural network (ANN) and the support vector machine (SVM), rough set theory is more suitable for solving problems related to decision-making in the field of management.

Due to the fact that the original rough set theory cannot process the preferential relationships between attributes [33,34], Greco, Matarazzo, Slowinski, et al. [35] expanded upon the theory. The expansion involves the replacement of indiscernibility relationships with dominant relationships in the rough approximation of decision attributes $[36,37]$. This replacement prevents the paradoxes that may be caused in the processing of sequential information by using the original RSA, which is based on equivalence relationships [38,39]. The expanded RSA has been applied in numerous fields of service, such as online open courses [37], pollution management strategy-making [40], airline performance evaluation [41], spare part classification [42], agricultural fund allocation [43], research and development project selection [44], financial performance evaluation [32], and pavement maintenance [31]. The definition and calculation procedures of this theory are as follows:

\section{Step 1: Information system}

There are four elements in the information system. It is expressed as follows: $I S=(U, Z, V, F)$, where $U$ represents a finite set of objects (global) and $U=\left\{x_{1}, x_{2}, \ldots, x_{n}\right\} ; Z=\left\{z_{1}, z_{2}, \ldots, z_{m}\right\}$ represents a finite set of attributes or criteria; $V_{z}$ is the range of the attribute criterion $z$, and $V=\cup_{z \in Z} V_{z}$; $f: U \times Z \rightarrow V$ is an information function, in which $z \in Z$ and $x \in U$. Moreover, $Z$ can be usually divided into $C$ (a set of condition attributes) and $D$ (a set of decision attributes).

Step 2: Rough approximation in the dominant relationship 
Let $S_{z}^{\geq}$be the dominant relationship pertinent to the attribute $z \in Z$ in the global $U$, that is, $x, y \in U$. Moreover, the term $x S_{z}^{\geq} y$ indicates that $x$ is not inferior to $y$ for the attribute $z$. Similarly, the term $S_{z}^{\geq}$ indicates that $x$ is absolutely dominant over $y$ for $z$, which is expressed as $x S_{z}^{\geq} y$. A strictly dominant relationship does not involve $x$ being equivalent to $y$ for $z$.

Let $C l=\left\{C l_{t}, t \in T\right\}, T=\{1,2, \ldots, n\}$ be the set of decision attributes $U$, and any $x \in U$ shall be categorized to a single class $\mathrm{Cl}_{t} \in C l$. If $r, s \in T$ and all $r>s$, then any element in $\mathrm{Cl}_{r}$ is dominant over all elements in $\mathrm{Cl}_{s}$. These unions are also referred to as upward or downward unions of classes, which are defined as $C l_{t}^{\geq}=\cup_{s \geq t} C l_{s}$ and $C l_{t}^{\leq}=\cup_{s \leq t} C l_{s}$, respectively. If $x$ dominates $y$ in the criterion of $P$ and the relationship is supported in all $z \in P, x S_{z}^{\geq} y$, then $X$ dominates $Y$ in the attribute set $P \subseteq C$, which is expressed as $x D_{P} y$.

If $P \subseteq C, x \in U$, then $D_{p}^{+}(x)=\left\{y \in U: y D_{P} x\right\}$ and $D_{p}^{-}(x)=\left\{y \in U: x D_{P} y\right\}$ are referred to as the $P$-dominating and $P$-dominated sets of $x$, respectively. The approximate upper or lower unions of these sets are known as granules of knowledge. The DRSA involves the use of these granules for approximate dominating or dominated sets.

The downward $(\underline{P})$ and upward $(\bar{P})$ approximates of $P \subseteq C$ and $C l_{t}^{\geq}, t \in\{2,3, \ldots, n\}$ are expressed as follows:

$$
\begin{gathered}
\underline{P}\left(C l_{t}^{\geq}\right)=\left\{x \in U: D_{P}^{+}(x) \subseteq C l_{t}^{\geq}\right\} \\
\bar{P}\left(C l_{t}^{\geq}\right)=\underset{X \in C l_{t}^{\geq}}{\cup} D_{P}^{+}(x)=\left\{x \in U: D_{P}^{-}(x) \cap C l_{t}^{\geq} \neq \varnothing\right\}
\end{gathered}
$$

where the downward and upward approximates are denoted as $\underline{P}\left(\mathrm{Cl}_{t}^{\geq}\right)$and $\bar{P}\left(\mathrm{Cl}_{t}^{\geq}\right)$, respectively.

Similarly, the downward $(\underline{P})$ and upward $(\bar{P})$ approximates of $P \subseteq C$ and $C l_{t}^{\leq}, t \in\{1,2, \ldots, n-1\}$ are defined as follows:

$$
\begin{gathered}
\underline{P}\left(C l_{t}^{\leq}\right)=\left\{x \in U: D_{P}^{-}(x) \subseteq C l_{t}^{\leq}\right\} \\
\bar{P}\left(C l_{t}^{\leq}\right)=\underset{X \in C l_{t}^{\leq}}{\cup} D_{P}^{-}(x)=\left\{x \in U: D_{P}^{+}(x) \cap C l_{t}^{\leq} \neq \varnothing\right\}
\end{gathered}
$$

where the downward and upward approximates are denoted as $\underline{P}\left(C l_{t}^{\leq}\right)$and $\bar{P}\left(C l_{t}^{\leq}\right)$, respectively.

For all $t \in\{1,2, \ldots, n\}$ and $P \subseteq C$, the downward $(\underline{P})$ and upward $(\bar{P})$ approximates satisfy the characteristics described in the following equations:

$$
\begin{gathered}
\underline{P}\left(C l_{t}^{\geq}\right) \subseteq C l_{t}^{\geq} \subseteq \bar{P}\left(C l_{t}^{\geq}\right), \underline{P}\left(C l_{t}^{\leq}\right) \subseteq C l_{t}^{\leq} \subseteq \bar{P}\left(C l_{t}^{\leq}\right) \\
\underline{P}\left(C l_{t}^{\geq}\right)=U-\bar{P}\left(C l_{t-1}^{\leq}\right), t=2, \ldots, n, \underline{P}\left(C l_{t}^{\leq}\right)=U-\bar{P}\left(C l_{t+1}^{\geq}\right), t=1,2, \ldots, n-1 \\
\bar{P}\left(C l_{t}^{\geq}\right)=U-\underline{P}\left(C l_{t-1}^{\leq}\right), t=2, \ldots, n, \bar{P}\left(C l_{t}^{\leq}\right)=U-\underline{P}\left(C l_{t+1}^{\geq}\right), t=1,2, \ldots, n-1 .
\end{gathered}
$$

The $P$-boundaries of $\mathrm{Cl}_{t}^{\geq}$and $\mathrm{Cl}_{t}^{\leq}$are defined as follows:

$$
\begin{aligned}
& B n_{P}\left(C l_{t}^{\geq}\right)=\bar{P}\left(C l_{t}^{\geq}\right)-\underline{P}\left(C l_{t}^{\geq}\right) \\
& B n_{P}\left(C l_{t}^{\leq}\right)=\bar{P}\left(C l_{t}^{\leq}\right)-\underline{P}\left(C l_{t}^{\leq}\right) .
\end{aligned}
$$

For all $t \in\{1,2, \ldots, n\}$ and $P \subseteq C$, the approximate accuracies of $C l_{t}^{\geq}$and $C l_{t}^{\leq}$are defined as follows:

$$
\alpha_{P}\left(C l_{t}^{\geq}\right)=\frac{\left|\underline{P}\left(C l_{t}^{\geq}\right)\right|}{\left|\bar{P}\left(C l_{t}^{\geq}\right)\right|}, \alpha_{P}\left(C l_{t}^{\leq}\right)=\frac{\left|\underline{P}\left(C l_{t}^{\leq}\right)\right|}{\left|\bar{P}\left(C l_{t}^{\leq}\right)\right|} .
$$


The approximate quality of the set of decision class $\mathrm{Cl}$ with regard to the attribute set $P$ is described as follows:

$$
\gamma_{P}(C l)=\frac{\left|U-\left(\underset{t \in\{2, \ldots, n\}}{U} B n_{P}\left(C l l_{t}^{\geq}\right)\right)\right|}{|U|}=\frac{\left|U-\left(U_{t \in\{1, \ldots, n-1\}}^{U} B n_{P}\left(C l_{t}^{\leq}\right)\right)\right|}{|U|} .
$$

The $|\cdot|$ is the cardinal number of the set. The rule definition class $\mathrm{Cl}$ calculated using the set $P \subseteq C$ has weak classification accuracy. All the goals in the data table are clearly defined. When $\gamma_{P}(\mathrm{Cl})=\gamma_{c}(\mathrm{Cl})$, any minimum subset $P \subseteq C$ is referred to as the reduct of $C$ in $C l$, which is expressed as $R E D_{C l}(P)$. More than one cut may be present in a data table, and all cut sets are known as cores, which are expressed as $C O R E_{C l}$.

\section{Step 3: Cores and reducts of attributes}

Cores and reducts of attributes are the two basic concepts of sets of approximation. When excessive condition attributes exist in an information system, eliminating these attributes does not affect the overall quality of decision-making. In other words, excessive attributes can be eliminated to create simplified sets of attributes. The reduced sets of attributes are then intersected to obtain the core attributes. Thus, the complexity of the system can be reduced, and the vectors that truly influence decision-making can be quickly presented.

\section{Step 4: Decision rules}

The information is expressed as several simple decision rules in the 'if-then' format. Dominant relationships are applied to identify decision rules with information on dominance [45]. The formats of the rules are as follows:

(1) $D_{\geq}$decision rule: if $f\left(x, z_{1}\right) \geq r_{z_{1}}$ and $f\left(x, z_{2}\right) \geq r_{z_{2}}$ and $\ldots f\left(x, z_{P}\right) \geq r_{z_{P}}$, then $x \in C l \geq$. This decision rule is only supported by the targets of the approximate of the lower boundary $\underline{P}$ in the classification set $C l_{t}^{\geq}$.

(2) $D_{\leq}$decision rule: if $f\left(x, z_{1}\right) \leq r_{z_{1}}$ and $f\left(x, z_{2}\right) \leq r_{z_{2}}$ and $\ldots f\left(x, z_{P}\right) \leq r_{z_{P}}$, then $x \in C l_{t}^{\leq}$. This decision rule is only supported by the targets of the approximate of the lower boundary $\underline{P}$ in the classification set $\mathrm{Cl}_{t}^{\leq}$.

(3) $D_{\geq_{\leq}}$decision rule: if $f\left(x, z_{1}\right) \geq r_{z_{1}}$ and $f\left(x, z_{2}\right) \geq r_{z_{2}}$ and $\ldots f\left(x, z_{k}\right) \geq r_{z_{k}}$ and $f\left(x, z_{k+1}\right) \leq r_{z_{k+1}}$ and $\ldots f\left(x, z_{P}\right) \leq r_{z_{P}}$, then $x \in C l_{t} \cup C l_{t+1} \cup \ldots \cup C l_{s}$. This decision rule is supported by the targets of the boundary $P$ in the classification sets $C l_{t}^{\leq}$and $C l_{t}^{\geq}$, where $P=\left\{z_{1}, z_{2}, \ldots, z_{P}\right\} \subseteq\left\{r_{z 1}, r_{z 2}, \ldots, r_{z P}\right\} \in$ $V_{z_{1}} \times V_{z_{2}} \times \ldots \times V_{z_{P}}$ and $t \in\{1, \ldots, n\}$.

\section{Empirical Study}

The results of an empirical analyzed on the competency assessment indicators, and performance data of Chinese ISEC teachers are presented in this section. The background and problems of the empirical case are first introduced, followed by the core attributes and decision rules derived using the DRSA. An in-depth discussion of the research results is then presented. Teacher $\alpha$ is used as an example for analyzing how the research results enabled decision makers to formulate an effective ESD competency improvement strategy for the existing faculty development system.

\subsection{Case Background and Problems}

According to the International Task Force on Teachers for Education 2030 [46], teacher training should be regarded as the frontier and hotspot of current efforts of ESD. Particular attention should be paid to the specific skills and abilities required by teachers in teaching during induction and in-service training. According to the aforementioned task force, developing countries and regions should increase resource investment in teacher training, create innovative training methods, and improve training efficiency. According to the direction and target of sustainable development proposed by the United Nations, the Chinese government implemented the ISEC program, which involves systematically training and developing university teachers [47]. This study focused on the items of the ISEC program for case analysis because of the following reasons: (1) the ISEC program is primarily 
implemented at Chinses regional universities, which comprise the highest number of teachers in China's higher education, thus, high research representativeness can be achieved; (2) the teachers who were investigated in the ISEC program are from many universities in different provinces, which further strengthens the data representativeness of this study with regard to the competency for ESD in regional university teachers in China; (3) ISEC is an early systematic program in China to explore the ESD competency of university teachers. Therefore, this study has not only guiding value for the improvement of teachers' ESD competency in the ISEC program, but also general reference significance for regional universities in China.

The ISEC program has built its own teachers' competency model. Based on this model, over the past eight years, the ISEC program [47] has provided systematic training to approximately 1,500 teachers in more than 30 regional universities in China. In particular, the training of teaching competencies is emphasized, and the central government proposed China's Education Modernization 2035 in February 2019. It emphasized the development of teachers' competency for ESD. Subsequently, the competency for ESD was incorporated in the existing ISEC teachers' competency model as a new indicator, and the training and development of ESD competencies for ISEC teachers were planned. After the competencies for ESD were incorporated into the ISEC model, the number of criteria evaluated in the model expanded from 9 to 10 . As presented in Table 1, the ten criteria were as follows: critical thinking $\left(C_{1}\right)$, instructional design $\left(C_{2}\right)$, learning assessment $\left(C_{3}\right)$, teaching in classrooms $\left(C_{4}\right)$, English as a medium of instruction $\left(C_{5}\right)$, textbook compilation $\left(C_{6}\right)$, curriculum development $\left(C_{7}\right)$, pedagogical innovation $\left(\mathrm{C}_{8}\right)$, international cooperation $\left(\mathrm{C}_{9}\right)$, and competency for $\operatorname{ESD}\left(\mathrm{C}_{10}\right)$. 
Table 1. ISEC teachers' competency model and the description of attributes.

\begin{tabular}{|c|c|c|c|c|}
\hline Attributes & Definitions and Explanations & Domain Values & Value Set & Preference \\
\hline \multicolumn{5}{|c|}{ Condition attributes } \\
\hline Critical Thinking $\left(C_{1}\right)$ & $\begin{array}{l}\text { The ability to analyze, verify, and judge the true value of things by using objective evaluation criteria } \\
\text { based on rational judgment. This ability not only requires critical thinking of the problems but also } \\
\text { reflects the "thinking itself" of critical thinking and shall be applied throughout all aspects of } \\
\text { teaching practice and life. }\end{array}$ & Poor; Medium; Good & $\{1,2,3\}$ & Ordered \\
\hline Instructional Design $\left(C_{2}\right)$ & $\begin{array}{l}\text { The ability of ISEC teachers to make the overall design of the teaching objectives, learning effect, } \\
\text { teaching methods, teaching plan, teaching resources, learning assessment, teaching disciplines, and } \\
\text { other teaching processes and organizational forms in terms of differentiated demands of students by } \\
\text { aiming at developing a syllabus based on the learning outcomes. }\end{array}$ & Poor; Medium; Good & $\{1,2,3\}$ & Ordered \\
\hline Learning assessment $\left(C_{3}\right)$ & $\begin{array}{l}\text { The ability of ISEC teachers to collect information from a variety of sources by using rubrics as one of } \\
\text { the evaluation tools and according to the teaching requirements of cultivating ISEC students' nine } \\
\text { abilities and consciousness, with formative evaluation as the main method, and the ability of teachers } \\
\text { to evaluate and analyze students' learning and cultivation by using the evaluation data. }\end{array}$ & Poor; Medium; Good & $\{1,2,3\}$ & Ordered \\
\hline Teaching in classroom $\left(\mathrm{C}_{4}\right)$ & $\begin{array}{l}\text { The ability of ISEC teachers to create an understanding and inclusive teaching atmosphere by using } \\
\text { the information and communication technology, and instruct students to learn and complete } \\
\text { professional teaching tasks by using the teaching methods that meet the needs of students through } \\
\text { the combination of the learning outcomes of ISEC courses delivery and by focusing on the objectives } \\
\text { of nine abilities and awareness cultivation of students. }\end{array}$ & Poor; Medium; Good & $\{1,2,3\}$ & Ordered \\
\hline $\begin{array}{l}\text { English as Medium } \\
\text { of Instruction }\left(\mathrm{C}_{5}\right)\end{array}$ & The ability of ISEC teachers to organize classroom teaching with English as the medium. & Poor; Medium; Good & $\{1,2,3\}$ & Ordered \\
\hline Textbook compilation $\left(\mathrm{C}_{6}\right)$ & $\begin{array}{l}\text { The ability of ISEC teachers to design and compile international curriculum materials with Chinese } \\
\text { characteristics based on the compilation of teaching materials, as well as the level of understanding } \\
\text { and cognition of textbook uniqueness, theory, preciseness, inspiration, and practicality. }\end{array}$ & Poor; Medium; Good & $\{1,2,3\}$ & Ordered \\
\hline Curriculum development $\left(\mathrm{C}_{7}\right)$ & $\begin{array}{l}\text { The ability of ISEC teachers to determine the ISEC curriculum objectives through student cultivation } \\
\text { needs analysis, choose teaching contents, and teaching activities of the subject based on this objective } \\
\text { and creatively plan, organize, implement, evaluate and revise, and finally achieve } \\
\text { the curriculum objectives. }\end{array}$ & Poor; Medium; Good & $\{1,2,3\}$ & Ordered \\
\hline Pedagogical innovation $\left(\mathrm{C}_{8}\right)$ & $\begin{array}{l}\text { The ability of ISEC teachers to study ISEC teaching-related issues in a well-directed, planned, and } \\
\text { organized manner by using scientific theory combining and innovating practical guidance for } \\
\text { improving the quality of ISEC teaching. }\end{array}$ & Poor; Medium; Good & $\{1,2,3\}$ & Ordered \\
\hline International cooperation $\left(\mathrm{C}_{9}\right)$ & $\begin{array}{c}\text { The ability of ISEC teachers to conduct cross-border, cross-cultural, and cross-disciplinary } \\
\text { cooperation through communication and negotiation with the participants of all cooperating parties } \\
\text { when getting involved in international education cooperation activities such as instructional design, } \\
\text { teaching research, curriculum development, etc. }\end{array}$ & Poor; Medium; Good & $\{1,2,3\}$ & Ordered \\
\hline \multicolumn{5}{|c|}{ Decision variable } \\
\hline Competency for ESD $\left(C_{10}\right)$ & $\begin{array}{l}\text { The ability of ISEC teachers to fulfil the responsibility of education for sustainable development. ISEC } \\
\text { teachers should guide students to establish the idea of sustainable development, acquire relevant } \\
\text { knowledge and abilities, improve the lifestyle, prepare to be responsible citizens in the future, and } \\
\text { contribute to the sustainable development of society, economics, environment, and culture. }\end{array}$ & Poor; Medium; Good & $\{1,2,3\}$ & Ordered \\
\hline
\end{tabular}




\subsection{Preparation of the Information Table and Primary Survey}

In July 2019, the ISEC management institution evaluated 225 ISEC university teachers by using the new ISEC teachers' competency model for the first time. These teachers were from 12 regional universities across five northern Chinese provinces (Figure 1). All ten criteria were listed on the information sheet for evaluation. In particular, competency for ESD $\left(\mathrm{C}_{10}\right)$ was defined as a decision attribute, whereas the remaining nine criteria were designated as condition attributes.

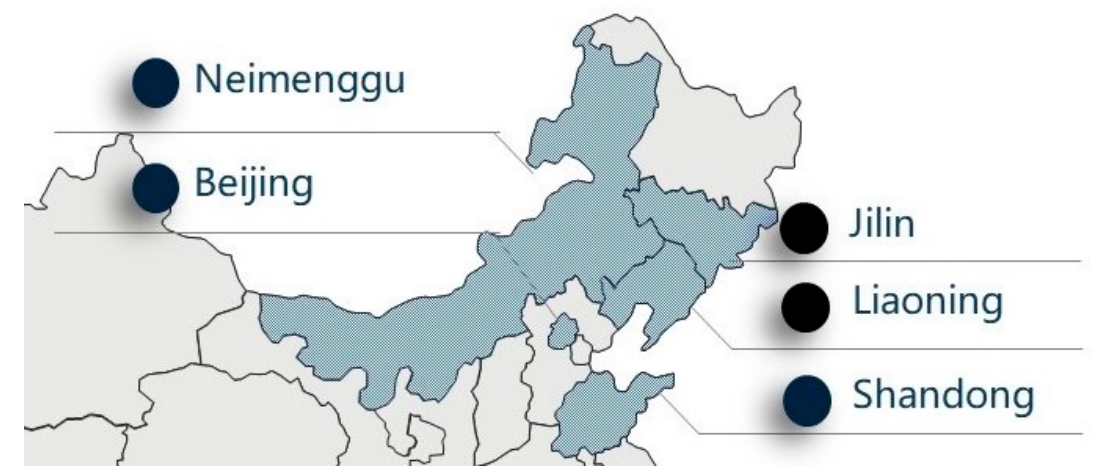

Figure 1. Those 12 universities are located in five provinces in northern China.

In addition, the 3-Likert scale in past studies is a common discrete method in general [48-51]. The benefit of it is that it can greatly reduce the number of rules to highlight the main rules and patterns between conditional attributes and decision attributes [52]. As a result, decision makers can more easily understand the management implications behind decision rules and develop various appropriate improvement strategies. For these reasons, the measurement scales of all attributes in this study were designed into 3-Likert scales. Preferences of attributes were defined as levels of competencies. The attributes/criteria for ISEC teachers' competencies are shown in Table 1. To assure the effectiveness of the assessment results and a balance in the number of data points, data cleansing and expert screening were conducted. A total of 156 high-quality data points were selected for further analysis (52 were selected for each level of the decision attributes).

\subsection{The Approximate Quality between the Accuracy and Boundary of the Decision Model}

JAMF software was developed by Poznan university of technology. The calculation of DRSA in this paper was implemented by JAMF software. To ensure the quality of the DRSA model, cross-validation was performed five times. A total of $80 \%$ of all the data were used as training data, and the remaining $20 \%$ data were used as test data. Three commonly employed data mining methods were used for accuracy comparison, namely the rough set approach (RSA), support vector machine (SVM), and artificial neural network (ANN). Although the DRSA was not the most accurate among the four methods, its standard deviation was the lowest (0.048), but the classification accuracy of the model also reached an average of 79.50\% in the 5-folds. Unlike SVM and ANN, the DRSA allows the relationship between the condition attributes and decision attribute to be described using the 'if-then' decision rule, which enables decision makers to understand actual behavior patterns of the model. SVM and ANN are referred to as black-box models because they do not allow such representation. In summary, the DRSA provides stable and comprehensible decision results with adequate accuracy and is suitable for application in management decision-making. The results of cross-validation confirmed correctness and validity of classification by DRSA in this study (Table 2). 
Table 2. Classification accuracy of various classifiers by 5 -folds.

\begin{tabular}{ccccc}
\hline No. & DRSA & RSA & SVM & ANN \\
\hline 1 & $78.13 \%$ & $74.19 \%$ & $81.25 \%$ & $87.50 \%$ \\
2 & $77.42 \%$ & $80.65 \%$ & $84.38 \%$ & $87.50 \%$ \\
3 & $87.10 \%$ & $64.52 \%$ & $87.50 \%$ & $90.63 \%$ \\
4 & $74.19 \%$ & $74.19 \%$ & $75.00 \%$ & $78.13 \%$ \\
5 & $80.65 \%$ & $64.52 \%$ & $71.88 \%$ & $81.25 \%$ \\
Average & $79.50 \%$ & $71.61 \%$ & $80.00 \%$ & $85.00 \%$ \\
SD & 0.048 & 0.070 & 0.065 & 0.051 \\
\hline
\end{tabular}

Table 3 lists the quality of approximation for the decision classes. The results showed that the decision classes have high approximation quality of the approximation. In other words, the condition attributes selected in this study were the approximations of the decision classes. The 'at most 1 ' class represented 'poor ESD competency'. Its lower approximation was 52 objects, and upper approximation was 53 objects, respectively, and the precision of approximation for this class was 0.981 . The 'at most 2 ' class represented 'medium ESD competency', and it had a lower approximation of 99 objects, and an upper approximation of 106 objects, the precision of approximation for this class was 0.934 . The 'at least 2' class also represented 'medium ESD competency', the precision of approximation for this class was 0.990. The 'at least 3' class represented 'good ESD competency', the precision of approximation for this class was 0.877 . The overall quality of the approximation was 0.949 .

Table 3. Quality of approximation for decision classes.

\begin{tabular}{ccccc}
\hline No. & At Most 1 & At Most 2 & At Least 2 & At Least 3 \\
\hline Lower approx. & 52 & 99 & 103 & 50 \\
Upper approx. & 53 & 106 & 104 & 57 \\
Boundary & 1 & 7 & 1 & 7 \\
Precision & 0.981 & 0.934 & 0.990 & 0.877 \\
\hline
\end{tabular}

\subsection{Reduced and Core Condition Attributes}

The DRSA, which is based on set theory, enables the reduction of condition attributes without affecting model accuracy. Three sets of reduced conditional attributes were derived. The intersections of the conditional attributes within these sets form indispensable conditional attributes for the decision model, which are also known as core attributes. In this study, the core attributes were critical thinking $\left(C_{1}\right)$, learning assessment $\left(C_{3}\right)$, English as medium of instruction $\left(C_{5}\right)$, curriculum development $\left(C_{7}\right)$, pedagogical innovation $\left(C_{8}\right)$, and international cooperation $\left(C_{9}\right)$ (Table 4$)$. Thus, these six core competencies are crucial indicators of the competency for ESD in the ISEC teachers' competency model. The teachers' performance on these six competencies influences their overall ESD competency levels considerably. 
Table 4. Reduct and core attributes.

\begin{tabular}{|c|c|}
\hline Reduct/Core & Attribute Set \\
\hline Reduct 1 & $\begin{array}{l}\text { Critical thinking }\left(C_{1}\right) \text {, Learning assessment }\left(C_{3}\right) \text {, Teaching in } \\
\text { classroom }\left(C_{4}\right) \text {, English as medium of instruction }\left(C_{5}\right) \text {, Textbook } \\
\text { compilation }\left(C_{6}\right) \text {, Curriculum development }\left(C_{7}\right) \text {, Pedagogical } \\
\text { innovation }\left(C_{8}\right) \text {, and International cooperation }\left(C_{9}\right)\end{array}$ \\
\hline Reduct 2 & $\begin{array}{l}\text { Critical thinking }\left(C_{1}\right) \text {, Instructional design }\left(C_{2}\right) \text {, Learning } \\
\text { assessment }\left(C_{3}\right) \text {, English as medium of instruction }\left(C_{5}\right) \text {, Textbook } \\
\text { compilation }\left(C_{6}\right) \text {, Curriculum development }\left(C_{7}\right) \text {, Pedagogical } \\
\text { innovation }\left(C_{8}\right) \text {, and International cooperation }\left(C_{9}\right)\end{array}$ \\
\hline Reduct 3 & $\begin{array}{l}\text { Critical thinking }\left(C_{1}\right) \text {, Instructional design }\left(C_{2}\right) \text {, Learning } \\
\text { assessment }\left(C_{3}\right) \text {, Teaching in classroom }\left(C_{4}\right) \text {, English as medium of } \\
\text { instruction }\left(C_{5}\right) \text {, Curriculum development }\left(C_{7}\right) \text {, Pedagogical } \\
\text { innovation }\left(C_{8}\right) \text {, and International cooperation }\left(C_{9}\right)\end{array}$ \\
\hline Core attributes & $\begin{array}{c}\text { Critical thinking }\left(C_{1}\right) \text {, Learning assessment }\left(C_{3}\right) \text {, English as } \\
\text { medium of instruction }\left(C_{5}\right) \text {, Curriculum development }\left(C_{7}\right) \text {, } \\
\text { Pedagogical innovation }\left(C_{8}\right) \text {, and International cooperation }\left(C_{9}\right)\end{array}$ \\
\hline
\end{tabular}

\subsection{Decision Rules-Based Appropriate Strategies to Improve Competency for ESD}

The analysis results for the core attributes and minimal coverage decision rules (Table A1 in Appendix A) provide a crucial reference to decision makers and managers for adjusting and improving the existing university faculty development system. In the present study, teacher $\alpha$ was selected as a target of analysis to examine the strategies to improve competency for ESD according to the results of DRSA.

In Table 5, the performance of the competencies of teacher $\alpha$ is listed. The decision rules listed in Table A1 enable decision makers to formulate feasible solutions to improve competency for ESD. The 'at least 3' class, which indicated satisfactory competency for ESD, featured five rules, which represent five possible solutions. Teachers classified into the other classes can reference these rules to enhance their competency for ESD to the level of the 'at least 3' class in accordance with the relevant competency indicators. To simplify the solutions, reduce their cost, and guarantee their effectiveness, the core attributes were combined with the decision rules to create simplified core decision rules (Table 6). Only three of the five rules in the 'at least 3' class were relevant to the core attributes. These three rules provide decision makers with a reference for formulating solutions. The simplified rules that were suggested enhanced the precision of resource input in the improvement of competencies, and they reduced the complexity of decision-making. The effectiveness of the improvement was also guaranteed. For example, if teacher $\alpha$ must be included in an ESD faculty development program by the university because of an objective reason, a solution must be created to improve $\alpha$ 's competency for ESD. According to the core decision rules in Table 6, decision makers can adopt three possible solutions: (1) use the existing teacher training system with an adjustment to a limited extent to improve teacher $\alpha$ 's competency in English as a medium of instruction $\left(C_{5}\right)$ to no lower than the 'medium' level and that in curriculum development $\left(C_{7}\right)$ to the 'good' level; (2) improve teacher $\alpha$ 's competency in English as a medium of instruction $\left(\mathrm{C}_{5}\right)$ and pedagogical innovation $\left(\mathrm{C}_{8}\right)$ to the 'good' level and that in international cooperation $\left(\mathrm{C}_{9}\right)$ to no lower than the 'medium' level; and (3) improve teacher $\alpha$ 's competency in learning assessment $\left(C_{3}\right)$ and English as a medium of instruction $\left(C_{5}\right)$ to the 'good' level and that in international cooperation $\left(\mathrm{C}_{9}\right)$ to no lower than the 'medium' level.

Table 5. Performance of the nine criteria of teacher $\alpha$.

\begin{tabular}{cccccccccc}
\hline Attributes & $C_{1}$ & $C_{2}$ & $C_{3}$ & $C_{4}$ & $C_{5}$ & $C_{6}$ & $C_{7}$ & $C_{8}$ & $C_{9}$ \\
\hline Value & 2 & 2 & 2 & 3 & 1 & 3 & 1 & 1 & 1 \\
\hline
\end{tabular}


Table 6. Rules considering the core attributes for "at least 3".

\begin{tabular}{|c|c|c|c|}
\hline No. & Conditions & Decision & Support Strength \\
\hline 1 & $\begin{array}{l}\text { English as medium of instruction } \\
\left.\left(C_{5}\right) \geq 2\right) \&(\text { Curriculum } \\
\left.\text { development }\left(C_{7}\right) \geq 3\right)\end{array}$ & $\mathrm{D} \geq 3$ & $25(16.0 \%)$ \\
\hline 2 & $\begin{array}{l}\text { (English as medium of instruction } \\
\left.\left(\mathrm{C}_{5}\right) \geq 3\right) \& \text { (Pedagogical innovation } \\
\left.\left(\mathrm{C}_{8}\right) \geq 3\right) \& \text { (International } \\
\left.\text { cooperation }\left(\mathrm{C}_{9}\right) \geq 2\right)\end{array}$ & $\mathrm{D} \geq 3$ & $23(14.7 \%)$ \\
\hline 3 & $\begin{array}{l}\left.\text { (Learning assessment }\left(C_{3}\right) \geq 3\right) \& \\
\text { English as medium of instruction } \\
\left.\left(C_{5}\right) \geq 3\right) \&(\text { International } \\
\left.\text { cooperation }\left(C_{9}\right) \geq 2\right)\end{array}$ & $\mathrm{D} \geq 3$ & $28(17.9 \%)$ \\
\hline
\end{tabular}

\section{Discussion}

This study aimed to assist decision makers with appropriately adjusting the existing teacher training system to enhance teachers' ESD competency without having to increase costs or abolish the existing system.

In practice, many universities have developed separate training plans targeting ESD competency on top of the existing programs in order to address sustainability challenges. Such a process, however, entails predicaments. Over years of operation, the original teacher training programs have occupied a large portion of resources for teacher development. The establishment of the new training system targeting ESD competency requires the investment of massive resources and a long-term construction process. For regional universities that are already struggling with limited resources, constructing a new teacher training system means that the original teacher training programs will have to face the consequences, like reduced resource input, disruption, or even abolishment, so that the limited resources can be diverted into the construction of the new training system. Nonetheless, the original teacher training program has been proven valuable for enhancing teachers' instructional competency. Against a backdrop where ESD competency is increasingly valued, regional universities with limited resources may be forced to renounce years worth of practices to cultivate traditional teaching competencies (for example, competencies represented by $C_{1}$ through $C_{9}$ in the ISEC teacher competency model). As a result, the training of teachers' competencies has attended to one thing and lost sight of another.

From the aspect of management connotations, the results of this research will facilitate regional universities to put the issue of teachers' ESD competency improvement in a more interconnected and integrative perspective. By organically integrating the original teacher competency training program with the new ESD competency training, universities can achieve codevelopment and growth of both traditional and ESD competency. Specifically, this research will provide implications for addressing the practical predicaments faced by universities from two aspects:

First, the identification of core attributes will provide guidance for universities, allowing them to realize that some traditional competency indicators can have significant influences on ESD competency, and well-targeted training of these traditional competencies facilitates the enhancement of ESD competency. For instance, the empirical case analysis described in Section 4 derived six core competency indicators, which were critical thinking $\left(\mathrm{C}_{1}\right)$, learning assessment $\left(\mathrm{C}_{3}\right)$, English as medium of instruction $\left(C_{5}\right)$, curriculum development $\left(C_{7}\right)$, pedagogical innovation $\left(C_{8}\right)$, and international cooperation $\left(C_{9}\right)$, respectively. Practically, ISEC is a program of the reformation in Chinese higher education. For the ISEC program, two innovative characteristics are distinct from the conventional higher education model in China. First, critical thinking is applied to all aspects of teaching activities; second, formative assessment is replacing the traditional educational practice based on test scores. Thus, critical thinking $\left(C_{1}\right)$ and learning assessment $\left(\mathrm{C}_{3}\right)$ are crucial in the ISEC-based ESD environment. Moreover, ISEC is a means of educational reform through internationalization, in which teachers are required to teach in both 
Mandarin and English. Therefore, English as a medium of instruction $\left(\mathrm{C}_{5}\right)$ and international cooperation $\left(C_{9}\right)$ have long been emphasized. Curriculum development $\left(C_{7}\right)$ and pedagogical innovation $\left(C_{8}\right)$ are indispensable for the dynamic improvement of teaching competency levels. Breakthrough curricula and teaching method innovations are problems that cannot be avoided in ESD. According to the analysis results, a high level of consistency was observed in the identification and practice of the core condition attributes. By implementing well-targeted training of these six traditional competencies through their existing teacher training programs, ISEC universities will also improve ESD competency.

Additionally, the decision-making rules will guide universities to adjust their original teacher training programs with of view of enhancing ESD competency. As shown by the empirical case analysis, on the one hand, decision-making rules assist universities with formulating ESD competency improvement strategies based on the competency performance of individual teachers (for example, the improvement strategies for teacher $\alpha$ proposed in Section 4.5). On the other hand, more importantly, the decision rules can guide the university to make an adjustment to the original teacher training plan for most teachers. In Appendix A, Table A1, there are four decision-making rules, which are rules $7,8,9$, and 11 , that have relatively high support strengths, reaching 86 objects ( $55.1 \%$ ), 83 objects $(53.2 \%), 84$ objects $(53.8 \%)$, and 88 objects $(56.4 \%)$, respectively. These values of support strengths indicate that for ISEC teachers, the four rules are of universal significances. Rule 7 shows that $55.1 \%$ of teachers who exhibit a 'medium' or higher level of performances in English as medium of instruction $\left(C_{5}\right)$ and pedagogical innovation $\left(C_{8}\right)$ also have a 'medium' or higher level of performances in ESD competency. According to Rule 8, 53.2\% of teachers who exhibit a 'medium' or higher level of performances in curriculum development $\left(\mathrm{C}_{7}\right)$ and pedagogical innovation $\left(\mathrm{C}_{8}\right)$ also have a 'medium' or higher level of performances in ESD competency. Rule 9 indicates that $53.8 \%$ of teachers who exhibit a 'medium' or higher level of performances in curriculum development $\left(C_{7}\right)$ and international cooperation $\left(\mathrm{C}_{9}\right)$ also have a 'medium' or higher level of performances in ESD competency. Rule 11 demonstrates that $56.4 \%$ of teachers who exhibit a medium or higher level of performances in instructional design $\left(C_{2}\right)$, textbook compilation $\left(C_{6}\right)$, and curriculum development $\left(C_{7}\right)$ also have a 'medium' or higher level of performances in ESD competency. The competency indicators as conditional attributes in rules 7, 8, and 9 are all core attributes. Based on the previous analysis of the impact of the four core attributes on ESD competency, the management implications for decision makers of these three rules are easy to understand. In particular, among the three conditional attributes of Rule 11, instructional design $\left(\mathrm{C}_{2}\right)$ and textbook compilation $\left(\mathrm{C}_{6}\right)$ are not core attributes. A teacher is required to have instructional design $\left(\mathrm{C}_{2}\right)$ and textbook compilation $\left(\mathrm{C}_{6}\right)$ competencies that are sufficient enough to address the new teaching content and objectives in the ESD teaching model. It is not difficult to find from the analysis of core attributes in Table 4 that these two competencies, when examined separately, each has considerably small influences on ESD competency. However, when the two competencies are organically combined and then integrated with curriculum development $\left(C_{7}\right)$, they impose significant impacts on ESD competency. Rule 11 's support strength of $56.4 \%$ is good proof of this. Rule 11 also further validates that it is necessary to discuss teachers' traditional competencies and ESD competency from an interconnected and integrative point of view in this research. ISEC universities should strengthen the training for some of the teachers' competences in their original teacher training programs in accordance with this set of rules, striving to facilitate teachers to reach the "good" level in terms of their critical thinking $\left(C_{1}\right)$ competency, and in the meantime, the "medium" level in other competencies like instructional design $\left(\mathrm{C}_{2}\right)$, English as medium of instruction $\left(C_{5}\right)$, textbook compilation $\left(C_{6}\right)$, curriculum development $\left(C_{7}\right)$, pedagogical innovation $\left(\mathrm{C}_{8}\right)$, and international cooperation $\left(\mathrm{C}_{9}\right)$. Such a strategy will allow the majority of ISEC teachers to enhance their ESD competency while improving their traditional competencies.

The previous research $[4,6,8,12,24,26,27]$ has attached much of its focus on the elements of ESD competency and the competency for ESD itself without connecting with teachers' traditional competencies. A small number of studies [16,22] have explored the impact of certain individual competencies of teachers on ESD competency. This research provides a new perspective for analyzing 
the influencing relationship between traditional competencies and ESD competency, and on this basis, assists decision makers with developing strategies for ESD competency improvement. The results show that some traditional competency indicators that actually have significant influential and promotive effects on competency for ESD, such as critical thinking, pedagogical innovation, and international cooperation, were not considered as elements of ESD competency in previous studies, nor have they been studied in connection with ESD competency.

\section{Conclusions}

This study aimed to assist decision makers in adjusting the existing teacher training system to a limited, but appropriate, extent for improving teachers' competency for ESD without incurring excessive costs and abolishing the existing system. In addition to increasing and reinforcing the training of core competencies, improvement suggestions should be provided for each teacher's specific competencies. Therefore, this study incorporated the DRSA to analyze the evaluation data on the competency for ESD in 156 ISEC university teachers in China. The six most critical competencies relative to the competency for ESD were identified from the nine existing competency indicators. The conditions and requirements for improving the competency for ESD to the 'good' level were also determined in the decision rules. This study was designed to assist decision makers in formulating appropriate and feasible improvement strategies that focus resources on the key competencies of teachers in accordance with the core attributes and decision rules within the existing faculty development system. Improvements in these key competencies will lead to the enhancement of competency for ESD. These improvement strategies eliminate the need to develop a new training system aimed specifically at competency for ESD. Only adjustments in the training resource investment of the existing nine teacher competencies are required. These strategies allow the competency for ESD to be significantly reinforced in a cost-effective manner. In this study, data mining was used to establish a model for university teachers' competency for ESD. The main contributions of this study lie in that, on the one hand, the data mining method has been introduced to the research field of ESD competency of university teachers, which is innovative in research methods for this topic; on the other hand, different from previous studies, the influence and improvement effect of traditional mature competency indicators on the emerging ESD competency have been studied, which gives a new perspective and a low-cost approach to the evaluation and improvement of the competency for ESD. Nevertheless, this study had certain limitations. (1) The number of data points employed in the data mining process was insufficient. Only 156 samples were selected, which may have affected the accuracy and representativeness of the research results. (2) Due to the data limitations, the background information of the research participants, such as sex, age, job title, education level, and the number of years of ESD participation, was not included in the analysis. This information may further optimize the research results and enhance the specificity of improvement suggestions for decision makers. In addition to improving the aforementioned two limitations, future studies should also investigate the relationship between the six core competency indicators, thereby further increasing the accuracy of suggestions for decision makers in improving competency for ESD.

Author Contributions: S.-S.W. provided research ideas and guided the entire research process. Y.L. wrote the content and collected information. Content and modified format of articles written by J.D. Y.-C.C. are responsible for the calculation of the method. All authors have read and agreed to the published version of the manuscript.

Funding: This research received no external funding.

Conflicts of Interest: The authors declare no conflict of interest. 


\section{Appendix A}

Table A1. Minimum cover rules.

\begin{tabular}{|c|c|c|c|}
\hline No. & Conditions & Decision & Support Strength \\
\hline 1 & $\begin{array}{c}\left.\text { (English as medium of instruction }\left(C_{5}\right) \geq 2\right) \& \text { (Curriculum } \\
\text { development }\left(C_{7}\right) \geq 3 \text { ) }\end{array}$ & $\mathrm{D} \geq 3$ & $25(16.0 \%)$ \\
\hline 2 & $\begin{array}{l}\left.\text { English as medium of instruction }\left(C_{5}\right) \geq 3\right) \&(\text { Pedagogical } \\
\left.\text { innovation }\left(C_{8}\right) \geq 3\right) \&\left(\text { International cooperation }\left(C_{9}\right) \geq 2 \text { ) }\right.\end{array}$ & $\mathrm{D} \geq 3$ & $23(14.7 \%)$ \\
\hline 3 & $\begin{array}{c}\left.\text { (Instructional design }\left(C_{2}\right) \geq 3\right) \& \text { (Pedagogical innovation }\left(C_{8}\right) \\
\geq 3) \&\left(\text { International cooperation }\left(C_{9}\right) \geq 2 \text { ) }\right.\end{array}$ & $\mathrm{D} \geq 3$ & $28(17.9 \%)$ \\
\hline 4 & $\begin{array}{c}\left.\text { (Learning assessment }\left(C_{3}\right) \geq 3\right) \&(\text { English as medium of } \\
\left.\text { instruction }\left(C_{5}\right) \geq 3\right) \&\left(\text { International cooperation }\left(C_{9}\right) \geq 2\right)\end{array}$ & $\mathrm{D} \geq 3$ & $28(17.9 \%)$ \\
\hline 5 & $\begin{array}{l}\left.\left.\text { (Critical thinking }\left(C_{1}\right) \geq 3\right) \& \text { (Learning assessment }\left(C_{3}\right) \geq 3\right) \& \\
\left.\text { (Teaching in classroom }\left(C_{4}\right) \geq 3\right) \& \text { (International cooperation } \\
\qquad\left(C_{9}\right) \geq 2 \text { ) }\end{array}$ & $\mathrm{D} \geq 3$ & $31(19.8 \%)$ \\
\hline 6 & $\begin{array}{c}\left.\text { (Learning assessment }\left(C_{3}\right) \geq 3\right) \& \text { (Pedagogical } \\
\text { innovation }\left(C_{8}\right) \geq 2 \text { ) }\end{array}$ & $\mathrm{D} \geq 2$ & $59(37.8 \%)$ \\
\hline 7 & $\begin{array}{c}\left.\text { (English as medium of instruction }\left(C_{5}\right) \geq 2\right) \& \text { (Pedagogical } \\
\left.\text { innovation }\left(C_{8}\right) \geq 2\right)\end{array}$ & $\mathrm{D} \geq 2$ & $86(55.1 \%)$ \\
\hline 8 & $\begin{array}{c}\text { (Curriculum development }\left(C_{7}\right) \geq 2 \text { ) \& (Pedagogical } \\
\text { innovation }\left(C_{8}\right) \geq 2 \text { ) }\end{array}$ & $\mathrm{D} \geq 2$ & $83(53.2 \%)$ \\
\hline 9 & $\begin{array}{c}\text { (Curriculum development }\left(C_{7}\right) \geq 2 \text { ) \& (International } \\
\text { cooperation }\left(C_{9}\right) \geq 2 \text { ) }\end{array}$ & $\mathrm{D} \geq 2$ & $84(53.8 \%)$ \\
\hline 10 & $\begin{array}{l}\left.\text { (Critical thinking }\left(C_{1}\right) \geq 3\right) \& \text { (English as medium of } \\
\left.\text { instruction }\left(C_{5}\right) \geq 2\right) \&\left(\text { Curriculum development }\left(C_{7}\right) \geq 2\right)\end{array}$ & $\mathrm{D} \geq 2$ & $56(35.8 \%)$ \\
\hline 11 & $\begin{array}{c}\left.\text { (Instructional design }\left(C_{2}\right) \geq 2\right) \& \text { (Textbook compilation }\left(C_{6}\right) \geq \\
\text { 2) \& (Curriculum development }\left(C_{7}\right) \geq 2 \text { ) }\end{array}$ & $\mathrm{D} \geq 2$ & $88(56.4 \%)$ \\
\hline 12 & $\begin{array}{c}\left.\text { (Curriculum development }\left(C_{7}\right) \leq 1\right) \& \text { (Pedagogical } \\
\left.\text { innovation }\left(C_{8}\right) \leq 1\right)\end{array}$ & $\mathrm{D} \leq 1$ & $38(24.3 \%)$ \\
\hline 13 & $\begin{array}{l}\left.\text { (Learning assessment }\left(C_{3}\right) \leq 2\right) \&(\text { English as medium of } \\
\left.\text { instruction }\left(C_{5}\right) \leq 1\right) \&\left(\text { Curriculum development }\left(C_{7}\right) \leq 1\right)\end{array}$ & $\mathrm{D} \leq 1$ & $30(19.2 \%)$ \\
\hline 14 & $\begin{array}{l}\left.\text { (Teaching in classroom }\left(C_{4}\right) \leq 2\right) \&(\text { English as medium of } \\
\left.\text { instruction }\left(C_{5}\right) \leq 1\right) \&\left(\text { Textbook compilation }\left(C_{6}\right) \leq 1\right)\end{array}$ & $\mathrm{D} \leq 1$ & $24(15.3 \%)$ \\
\hline 15 & $\begin{array}{c}\left.\text { (Critical thinking }\left(C_{1}\right) \leq 2\right) \&\left(\text { Curriculum development }\left(C_{7}\right) \leq\right. \\
2) \&\left(\text { Pedagogical innovation }\left(C_{8}\right) \leq 1\right) \& \text { (International } \\
\left.\text { cooperation }\left(C_{9}\right) \leq 1\right)\end{array}$ & $\mathrm{D} \leq 1$ & $42(29.6 \%)$ \\
\hline 16 & (International cooperation $\left(C_{9}\right) \leq 1$ ) & $\mathrm{D} \leq 2$ & $69(44.2 \%)$ \\
\hline 17 & $\begin{array}{c}\left.\text { (Instructional design }\left(C_{2}\right) \leq 2\right) \& \text { (Teaching in classroom }\left(C_{4}\right) \leq \\
\text { 2) \& (Pedagogical innovation }\left(C_{8}\right) \leq 2 \text { ) }\end{array}$ & $\mathrm{D} \leq 2$ & $72(46.1 \%)$ \\
\hline 18 & $\begin{array}{c}\left.\text { (Instructional design }\left(C_{2}\right) \leq 2\right) \& \text { (Learning assessment }\left(C_{3}\right) \leq \\
\left.\text { 2) \& (Curriculum development }\left(C_{7}\right) \leq 2\right)\end{array}$ & $\mathrm{D} \leq 2$ & $77(49.3 \%)$ \\
\hline 19 & $\begin{array}{c}\left.\left.\text { (Critical thinking }\left(C_{1}\right) \leq 2\right) \& \text { (Learning assessment }\left(C_{3}\right) \leq 2\right) \& \\
\left.\text { (Pedagogical innovation }\left(C_{8}\right) \leq 2\right)\end{array}$ & $\mathrm{D} \leq 2$ & $67(42.9 \%)$ \\
\hline 20 & $\begin{array}{l}\left.\text { (Learning assessment }\left(C_{3}\right) \leq 2\right) \& \text { (Curriculum development } \\
\left.\quad\left(C_{7}\right) \leq 2\right) \&\left(\text { Pedagogical innovation }\left(C_{8}\right) \leq 2\right)\end{array}$ & $\mathrm{D} \leq 2$ & $77(49.3 \%)$ \\
\hline 21 & $\begin{array}{c}\left.\text { (Critical thinking }\left(C_{1}\right) \leq 2\right) \&(\text { English as medium of } \\
\left.\text { instruction }\left(C_{5}\right) \leq 2\right) \&\left(\text { Curriculum development }\left(C_{7}\right) \leq 2\right) \& \\
\left(\text { Pedagogical innovation }\left(C_{8}\right) \leq 2\right)\end{array}$ & $\mathrm{D} \leq 2$ & $71(45.5 \%)$ \\
\hline
\end{tabular}

Note: the value in parentheses is strength of the percentages.

\section{References}

1. UNESCO. International Task Force on Teachers for Education 2030: Strategic Plan 2018-2021. Available online: http://www.unesco.org/new/fileadmin/MULTIMEDIA/FIELD/Beirut/video/TF.pdf (accessed on 29 December 2019). 
2. The State Council of China. China's Education Modernization 2035. Available online: http://www.gov.cn/ zhengce/2019-02/23/content_5367987.htm (accessed on 29 December 2019).

3. Summers, M.; Corney, G.; Childs, A. Student teachers' conceptions of sustainable development: The starting-points of geographers and scientists. Educ. Res. 2004, 46, 163-182. [CrossRef]

4. Bertschy, F.; Künzli, C.; Lehmann, M. Teachers' Competencies for the Implementation of Educational Offers in the Field of Education for Sustainable Development. Sustainability 2013, 5, 5067-5080. [CrossRef]

5. Yuniarti, Y.S.; Hasan, R.; Ali, M. Competencies of Education for Sustainable Development Related to Mathematics Education in Senior High School. J. Phys. Conf. Ser. 2019, 1179, 012075. [CrossRef]

6. Rauch, F.; Steiner, R. Competences for education for sustainable development in teacher education. CEPS J. 2013, 3, 9-24.

7. Adomßent, M.; Hoffmann, T. The Concept of Competencies in the Context of Education for Sustainable Development (ESD). Available online: https://pdfs.semanticscholar.org/9ec3/118c915b2b11fd1017a 1691398346f46af45.pdf (accessed on 27 March 2020).

8. Parker, J. Competencies for interdisciplinarity in higher education. Int. J. Sustain. High. Educ. 2010, 11, 325-338. [CrossRef]

9. UNESCO. We Must Support Our Teachers. Available online: http://uis.unesco.org/en/blog/we-must-supportour-teachers (accessed on 29 December 2019).

10. UNCED. Earth Summit Agenda 21. Available online: https://www.un.org/esa/dsd/agenda21/ (accessed on 29 December 2019).

11. De Haan, G. The BLK '21'programme in Germany: A 'Gestaltungskompetenz'-based model for Education for Sustainable Development. Environ. Educ. Res. 2006, 12, 19-32. [CrossRef]

12. Burmeister, M.; Rauch, F.; Eilks, I. Education for Sustainable Development (ESD) and chemistry education. Chem. Educ. Res. Pract. 2012, 13, 59-68. [CrossRef]

13. Lederman, N.G.; Abell, S.K. Handbook of Research on Science Education; Routledge: Abingdon-on-Thames, UK, 2014; Volume 2.

14. Mochizuki, Y.; Fadeeva, Z. Competences for sustainable development and sustainability: Significance and challenges for ESD. Int. J. Sustain. High. Educ. 2010, 11, 391-403. [CrossRef]

15. Weinert, F.E. Concept of Competence: A Conceptual Clarification. Available online: https://pdfs. semanticscholar.org/8b88/efa9dd5e0a4b605aea6e5e3b9ec640beb089.pdf (accessed on 28 March 2020).

16. Bürgener, L.; Barth, M. Sustainability competencies in teacher education: Making teacher education count in everyday school practice. J. Clean. Prod. 2018, 174, 821-826. [CrossRef]

17. Sadler, T.D.; Zeidler, D.L. Scientific literacy, PISA, and socioscientific discourse: Assessment for progressive aims of science education. J. Res. Sci. Teach. Off. J. Natl. Assoc. Res. Sci. Teach. 2009, 46, 909-921. [CrossRef]

18. Ware, S.A. Teaching chemistry from a societal perspective. Pure Appl. Chem. 2001, 73, 1209-1214. [CrossRef]

19. Marks, R.; Eilks, I. Promoting Scientific Literacy Using a Sociocritical and Problem-Oriented Approach to Chemistry Teaching: Concept, Examples, Experiences. Int. J. Environ. Sci. Educ. 2009, 4, 231-245.

20. Adomssent, M.; Godemann, J.; Michelsen, G.; Barth, M.; Rieckmann, M.; Stoltenberg, U. Developing key competencies for sustainable development in higher education. Int. J. Environ. Sci. Educ. 2007, 8, 416-430.

21. Tomas, L.; Girgenti, S.; Jackson, C. Pre-service teachers' attitudes toward education for sustainability and its relevance to their learning: Implications for pedagogical practice. Environ. Educ. Res. 2017, 23, 324-347. [CrossRef]

22. Lozano, R.; Barreiro-Gen, M.; Lozano, F.J.; Sammalisto, K. Teaching Sustainability in European Higher Education Institutions: Assessing the Connections between Competences and Pedagogical Approaches. Sustainability 2019, 11, 1602. [CrossRef]

23. Selvi, K. Teachers' competencies. Int. J. Philos. Cult. Axiolog. 2010, 7, 167-175. [CrossRef]

24. Sleurs, W. Competencies for ESD (Education for Sustainable Development) Teachers: A Framework to Integrate ESD in the Curriculum of Teacher Training Institutes; UNECE: Geneva, Switzerland, 2008.

25. Wals, A.E. Shaping the Education of Tomorrow: 2012 Full-length Report on the UN Decade of Education for Sustainable Development; UNESCO: Paris, France, 2012.

26. United Nations Economic Commission for Europe. Learning for the Future: Competences in Education for Sustainable Development 2012. Available online: http://www.unece.org/fileadmin/DAM/env/esd/ESD_ Publications/Competences_Publication.pdf (accessed on 29 December 2019). 
27. Vare, P.; Arro, G.; de Hamer, A.; Del Gobbo, G.; de Vries, G.; Farioli, F.; Kadji-Beltran, C.; Kangur, M.; Mayer, M.; Millican, R.; et al. Devising a Competence-Based Training Program for Educators of Sustainable Development: Lessons Learned. Sustainability 2019, 11, 1890. [CrossRef]

28. Pawlak, Z. Rough sets. Int. J. Comput. Inf. Sci. 1982, 11, 341-356. [CrossRef]

29. Liou, J.J.; Chuang, Y.-C.; Hsu, C.-C. Improving airline service quality based on rough set theory and flow graphs. J. Ind. Prod. Eng. 2016, 33, 123-133. [CrossRef]

30. Pawlak, Z. Rough set approach to knowledge-based decision support. Eur. J. Oper. Res. 1997, 99, 48-57. [CrossRef]

31. Augeri, M.G.; Greco, S.; Nicolosi, V. Planning urban pavement maintenance by a new interactive multiobjective optimization approach. Eur. Transp. Res. Rev. 2019. [CrossRef]

32. Shen, K.Y.; Yan, M.R.; Tzeng, G.H. Exploring R and D influences on financial performance for business sustainability considering dual profitability objectives. Sustainability 2017, 9, 1964. [CrossRef]

33. Greco, S.; Matarazzo, B.; Slowinski, R. Rough sets theory for multicriteria decision analysis. Eur. J. Oper. Res. 2001, 129, 1-47. [CrossRef]

34. Wang, S.; Li, T.; Luo, C.; Chen, H.; Fujita, H. Domain-wise approaches for updating approximations with multi-dimensional variation of ordered information systems. Inf. Sci. 2019, 478, 100-124. [CrossRef]

35. Greco, S.; Matarazzo, B.; Slowinski, R.; Tsoukiàs, A. Exploitation of a rough approximation of the outranking relation in multicriteria choice and ranking. In Trends in Multicriteria Decision Making; Springer: Berlin, Germany, 1998; pp. 45-60.

36. Barbati, M.; Greco, S.; Kadziński, M.; Słowiński, R. Optimization of multiple satisfaction levels in portfolio decision analysis. Omega 2018, 78, 192-204. [CrossRef]

37. Bouzayane, S.; Saad, I. A preference ordered classification to leader learners identification in a MOOC. J. Decis. Syst. 2017, 26, 189-202. [CrossRef]

38. Wang, S.; Li, T.; Luo, C.; Hu, J.; Fujita, H.; Huang, T. A novel approach for efficient updating approximations in dynamic ordered information systems. Inf. Sci. 2020, 507, 197-219. [CrossRef]

39. Zhang, X.; Chen, D.; Tsang, E.C.C. Generalized dominance rough set models for the dominance intuitionistic fuzzy information systems. Inf. Sci. 2017, 378, 1-25. [CrossRef]

40. Chen, R.; Xiong, Y.; Li, J.; Teng, Y.; Chen, H.; Yang, J. Comparison of multi-criteria analysis methodologies for the prioritization of arsenic-contaminated sites in the southwest of China. Environ. Sci. Pollut. Res. 2019, 26, 11781-11792. [CrossRef]

41. Gudiel Pineda, P.J.; Liou, J.J.H.; Hsu, C.C.; Chuang, Y.C. An integrated MCDM model for improving airline operational and financial performance. J. Air Transp. Manag. 2018, 68, 103-117. [CrossRef]

42. Hu, Q.; Chakhar, S.; Siraj, S.; Labib, A. Spare parts classification in industrial manufacturing using the dominance-based rough set approach. Eur. J. Oper. Res. 2017, 262, 1136-1163. [CrossRef]

43. Ottomano Palmisano, G.; Govindan, K.; Boggia, A.; Loisi, R.V.; De Boni, A.; Roma, R. Local Action Groups and Rural Sustainable Development. A spatial multiple criteria approach for efficient territorial planning. Land Use Policy 2016, 59, 12-26. [CrossRef]

44. Shen, K.Y. Compromise between short- and long-term financial sustainability: A hybrid model for supporting R \& D decisions. Sustainability 2017, 9, 375. [CrossRef]

45. Greco, S.; Matarazzo, B.; Slowinski, R.; Stefanowski, J. An algorithm for induction of decision rules consistent with the dominance principle. In Rough Sets and Current Trends in Computing. RSCTC 2000. Lecture Notes in Computer Science; Ziarko, W., Yao, Y., Eds.; Springer: Berlin, Germany, 2001.

46. UNESCO. Strengthening Teacher Education: A Prerequisite for Quality Teaching and Learning. Available online: https:/en.unesco.org/events/11th-policy-dialogue-forum-international-task-force-teacherseducation-2030 (accessed on 29 December 2019).

47. Weng, S.-S.; Liu, Y.; Chuang, Y.-C. Reform of Chinese Universities in the Context of Sustainable Development: Teacher Evaluation and Improvement Based on Hybrid Multiple Criteria Decision-Making Model. Sustainability 2019, 11, 5471. [CrossRef]

48. Liou, J.J.H. A novel decision rules approach for customer relationship management of the airline market. Expert Syst. Appl. 2009, 36, 4374-4381. [CrossRef]

49. Liou, J.J.H.; Yen, L.; Tzeng, G.-H. Using decision rules to achieve mass customization of airline services. Eur. J. Oper. Res. 2010, 205, 680-686. [CrossRef] 
50. Shen, K.-Y.; Hu, S.-K.; Tzeng, G.-H. Financial modeling and improvement planning for the life insurance industry by using a rough knowledge based hybrid MCDM model. Inf. Sci. 2017, 375, 296-313. [CrossRef]

51. Shen, K.-Y.; Sakai, H.; Tzeng, G.-H. Multi-graded Hybrid MRDM Model for Assisting Financial Performance Evaluation Decisions: A Preliminary Work; Mihálydeák, T., Min, F., Wang, G., Banerjee, M., Düntsch, I., Suraj, Z., Ciucci, D., Eds.; Springer International Publishing: Cham, Switzerland, 2019; pp. 439-453.

52. Liou, J.J.H.; Chuang, Y.-C.; Zavadskas, E.K.; Tzeng, G.-H. Data-driven hybrid multiple attribute decision-making model for green supplier evaluation and performance improvement. J. Clean. Prod. 2019, 241, 118321. [CrossRef]

(C) 2020 by the authors. Licensee MDPI, Basel, Switzerland. This article is an open access article distributed under the terms and conditions of the Creative Commons Attribution (CC BY) license (http://creativecommons.org/licenses/by/4.0/). 